\title{
ESTUDIO DE LA DEMANDA DEL TURISMO EN EL PARQUE NACIONAL Y RESERVA DE LA BIOSFERA DE MONFRAGÜE
}

\author{
Felipe Leco Berrocal \\ Ana Beatriz Mateos Rodríguez. \\ Antonio Pérez Díaz \\ Universidad de Extremadura
}

\section{RESUMEN}

El objetivo de este trabajo ha sido la realización de un diagnóstico exhaustivo del turismo en el Parque Nacional y la Reserva de la Biosfera de Monfragüe ${ }^{1}$. Para ello se han analizado algunos indicadores como el perfil del visitante, los alojamientos utilizados o a las actividades que se han llevado a cabo. Los datos, obtenidos a partir de las encuestas realizadas al efecto, han posibilitado una evaluación objetiva y precisa del perfil del turista en este espacio protegido, exponiendo las fortalezas y oportunidades de este territorio y subrayando la valoración afectiva o la fidelidad de los usuarios hacia este espacio protegido.

Palabras clave: turismo, desarrollo local, espacio natural protegido.

\section{Evaluation of tourism in the National Park and Biosphere Reserve Monfragüe}

\section{ABSTRACT}

The objective of this work has been conducting a thorough diagnosis of tourism in the National Park and Biosphere Reserve Monfragüe. Analyzed for this some indicators such as visitor profile, accommodations used or activities that have been carried out. The data

Recibido: 20 de diciembre de 2013

Devuelto para su revisión: 4 de abril de 2014

Aceptado: 6 de octubre de 2014

Grupos de Estudios sobre Desarrollo Rural y Local en Espacios de Frontera (GEDERUL). Instituto de Investigación en Patrimonio (I-PAT). Universidad de Extremadura.

Departamento de Arte y Ciencias del Territorio. Universidad de Extremadura. Avda de la Universidad, s/n. 10003 CÁCERES (España).E-mail: fleco@unex.es, abmateos@unex.es, aperez@unex.es

1 Título del proyecto: Las áreas de uso público en la Reserva de la Biosfera de Monfragüe. Accesibilidad y capacidad de carga. Referencia: Orden MAM 321/2007 (N Exp. 024/SGTB/2007 4.1). I.P.: Felipe Leco Berrocal. 
obtained from the surveys have enabled an objective and accurate assessment of the profile of tourists in this protected area, exposing the strengths and opportunities of the territory, stressing the affective valuation or user loyalty to this protected area.

Key words: turisme, local development, natural protected areas.

\section{INTRODUCCIÓN}

\subsection{Sobre los espacios naturales protegidos}

Los espacios naturales protegidos se han convertido en los últimos años en una nueva demanda y recurso de las sociedades actuales, de indudable valor social y económico (Muñoz, 2008; Corraliza et al., 2002). Esa incipiente demanda conlleva la consideración de éstos como objeto de consumo de las sociedades urbanas a través del turismo rural $\mathrm{u}$ otras tipologías de ocio. Quizás, por ello, cabría la posibilidad de considerarlos como parte de los espacios urbanos en sentido amplio, si bien actualmente, son elementos básicos del espacio rural (Tulla et al., 2008). Por esa misma razón, es necesario establecer estrategias de desarrollo que tengan en cuenta estas dinámicas económicas y territoriales. De ahí que el conocimiento exhaustivo del turismo en cada espacio natural protegido sea necesario para poder establecer las pautas de gestión en el desarrollo territorial en cada territorio concreto.

En todo caso, más allá del marco puramente administrativo, el área de influencia socioeconómica del Parque Nacional de Monfragüe (Figura 1) cuenta entre sus límites con unos grupos humanos que tienen un determinado grado de desarrollo social, económico y cultural que se nos antojan fundamentales en el devenir de estos espacios y por ende en el desarrollo endógeno de los mismos. Es por ello que para estimular el desarrollo de un territorio es necesaria la cohesión y participación social - partnership - (Gómez, 2002; Hummel, 2001; Kóhler, 2001).

Tampoco debemos pasar por alto que la introducción de la nueva imagen sobre la protección de la naturaleza no deja de ser una idea contradictoria en los medios rurales, en los que generalmente los grupos humanos tradicionalmente tienen una mentalidad más conservadora (Alvarado, 2007). Además, esa demanda de «naturaleza» tiene un marchamo netamente urbano, lo que la hace doblemente contradictoria ya que en pocos casos va acompañada de un oportuno conocimiento del territorio.

No cabe duda de que los recursos naturales y, en general, los espacios protegidos pueden constituir un buen impulso de salida para la puesta en marcha de múltiples iniciativas de desarrollo rural, en muchos casos utilizando el turismo como pieza clave de la diversificación económica en comarcas deprimidas (García, 2011; Hernández et al., 2011; Leco et al, 2013). De hecho, el amparo de un espacio natural bajo cualquier figura de protección puede llevar consigo innumerables y cuantiosos beneficios, tanto tangibles como intangibles (Azqueta, 1997; Sotelo, 2006; Rodríguez, 2009; Hidalgo-Fernández et al., 2013). No obstante, tampoco debe ignorarse que la mayoría de estos territorios presentan unos bajos indicadores socioeconómicos (Pascual, 2007; García et al., 2012). 


\subsection{El territorio de estudio}

El ámbito territorial del estudio comprende los catorce términos municipales que ocupa la Reserva de la Biosfera de Monfragüe (declarada en julio de 2003 por el Programa MaB de la UNESCO), que es justamente el espacio que ocupa la Zona de Especial Protección de Aves de Monfragüe y Dehesas del Entorno (Directiva CEE/409/79; declarada en 1991 y ampliada en 2004) alcanzando una superficie de 116.160 ha. Esos términos municipales son Casas de Millán, Casatejada, Deleitosa, Higuera, Mirabel, Romangordo y Saucedilla. A ellos hemos de unir los municipios que integran el Parque Nacional de Monfragüe (Ley 1/2007, de 2 de marzo): Casas de Miravete, Jaraicejo, Malpartida de Plasencia, Serradilla, Serrejón, Toril y Torrejón el Rubio (Leco, 2010). En todo caso, ese ámbito territorial de estudio se amplió finalmente al Área de Influencia Socioecónómica de la Reserva alcanzando las 195.502 ha.

Figura 1

\section{LOCALIZACIÓN GEOGRÁFICA DE LA ZONA DE ESTUDIO}

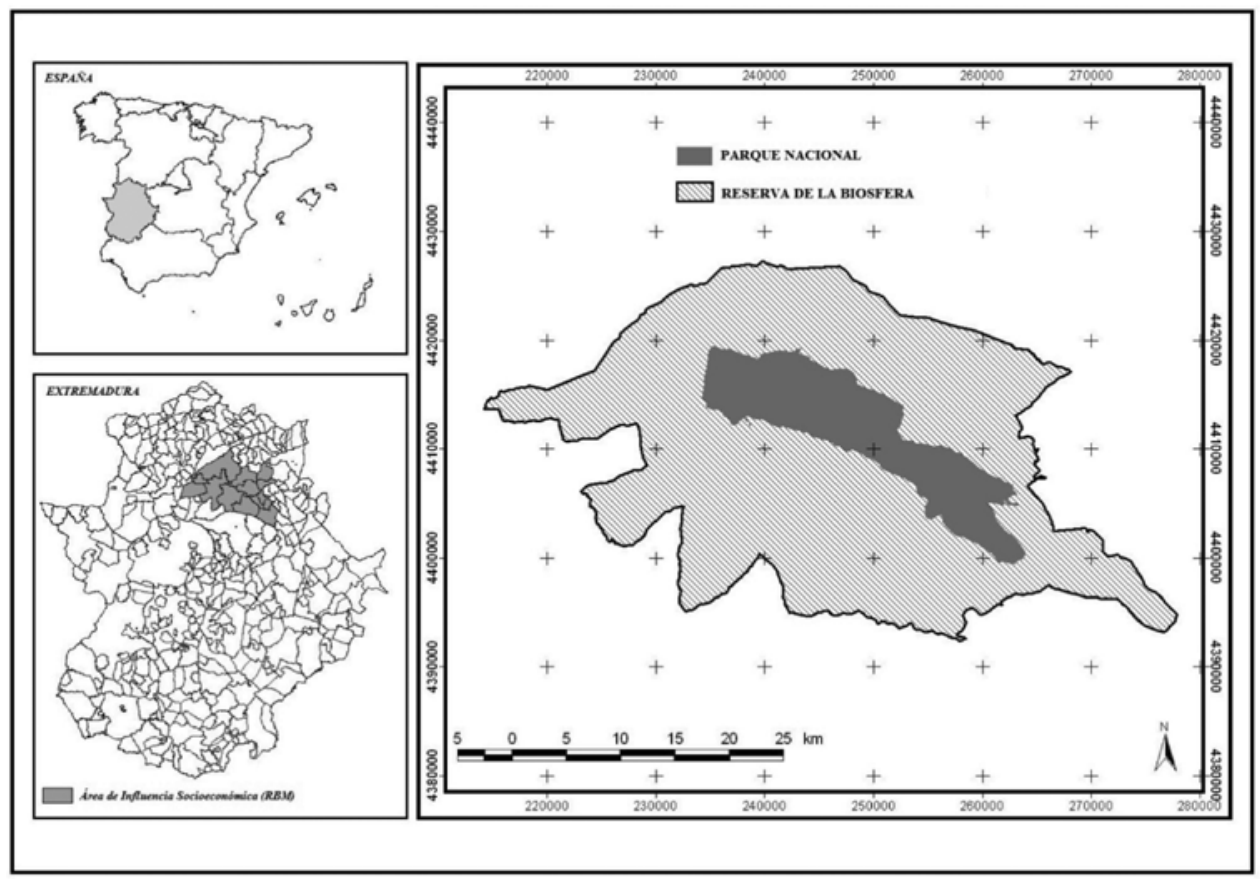

Fuente: Elaboración propia.

Desde el punto de vista demográfico, una de las características más destacadas de territorio de estudio es su debilidad poblacional. La densidad demográfica apenas llega a 6,7 habitantes $/ \mathrm{km}^{2}$, cifra ésta que dista mucho de los 26,2 habitantes $/ \mathrm{km}^{2}$ de la media regional y un abismo de los 89 habitantes $/ \mathrm{km}^{2}$ de la media española (Leco et al., 2012). La población actual tan sólo representa un 40,8\% de la contabilizada en 1960 y es inferior en 
un 26,3\% a la censada en 1900. El éxodo rural de los años sesenta del siglo pasado marcó para siempre el devenir demográfico de este territorio al provocar no sólo una merma poblacional, sino también unos desequilibrios estructurales que agravan sobremanera la amenaza de despoblación: los niveles de envejecimiento demográfico se aproximan a índices del 190\%, el problema de masculinización es ostensible en todas las edades inferiores a sesenta años y el crecimiento natural arroja saldos negativos desde finales de la década de los ochenta del pasado siglo.

Tampoco han sido ajenos a este proceso, el predominio superficial de las grandes propiedades y la práctica de actividades agrarias de carácter extensivo, basadas tradicionalmente en los aprovechamientos ganaderos y forestales, y que han actuado históricamente como factores de rechazo poblacional que, conjuntamente, sirvieron para animar el proceso emigratorio de la segunda mitad del siglo XX y con ello reducir de forma drástica el tamaño poblacional de los municipios de la zona.

Debe significarse que la producción agraria en el área de estudio mantiene los mismos rasgos de extensividad en los aprovechamientos agroforestales que lo caracterizaron durante siglos. Es así, como, pese a la modernización de la actividad agraria, el bosque mediterráneo de quercíneas tropieza con limitaciones agrológicas que requieren explotaciones de gran tamaño y que dificultan y desaconsejan la intensificación productiva, limitando con ello la rentabilidad de las pequeñas empresas y sus posibilidades para diversificar sus producciones.

Por otro lado, desde el punto de vista socioeconómico ninguno de los municipios del área de influencia socioeconómica ha logrado desprenderse de la dependencia agraria que tradicionalmente ha caracterizado su economía (Leco et al., 2012). La agricultura sigue siendo uno de los sectores de actividad que aglutina más trabajadores, como corresponde a un territorio que tiene un alto grado de ruralidad (42\%, que es el peso que tiene en la zona la población residente en núcleos con densidad inferior a los 10 habitantes $/ \mathrm{km}^{2}$ ). Es así como se puede explicar que los activos agrarios alcancen el 23,3\%. A ello hemos de unir el efecto centralizador que tiene el municipio de Malpartida de Plasencia en Monfragüe, ya que al aglutinar el $36 \%$ de la población total (Cuadro 1), inexorablemente también concentra el 48,3\% de los trabajadores de la industria, el 46,2\% de los trabajadores de la construcción y el 38,6\% de los trabajadores del sector servicios (Instituto de Estadística de Extremadura, 2013).

\subsection{Los valores de Monfragüe como destino turístico}

Es difícil concretar en unas líneas los muchos y variados atractivos que otorgan al territorio «Monfragüe» unos valores excepcionales como destino turístico. Entre otras, las especiales características físico-geográficas de este territorio, especialmente vinculadas al carácter fragoso del terreno y a la escasa profundidad y elevada erosionabilidad de los suelos, son algunas de las razones que ayudan a entender la escasa presencia humana sobre el territorio, circunstancia ésta que indudablemente ha sido garante de una calidad ambiental excepcional, no sólo por la singularidad y riqueza faunística que alberga Monfragüe (más de 280 especies de vertebrados), sino también por la variedad de ecosistemas que alberga y a su espectacularidad paisajística. 
Cuadro 1

DATOS MUNICIPALES BÁSICOS: SUPERFICIE MUNICIPAL, POBLACIÓN, DENSIDAD DE POBLACIÓN Y AFILIADOS A LA SEGURIDAD SOCIAL, 2013 (RESERVA DE LA BIOSFERA DE MONFRAGÜE)

\begin{tabular}{|l|r|r|r|r|r|r|r|}
\hline \multicolumn{1}{|c|}{ Municipios } & $\begin{array}{c}\text { Superf. } \\
\mathrm{km}^{2}\end{array}$ & $\begin{array}{c}\text { Número } \\
\text { Habitantes }\end{array}$ & $\begin{array}{c}\text { Habitantes/ } \\
\mathrm{km}^{2}\end{array}$ & $\begin{array}{c}\text { \% } \\
\text { Agricultura }\end{array}$ & $\begin{array}{c}\% \\
\text { Industria }\end{array}$ & $\begin{array}{c}\text { \% } \\
\text { Construcción }\end{array}$ & $\begin{array}{c}\% \\
\text { Servicios }\end{array}$ \\
\hline $\begin{array}{l}\text { Casas de } \\
\text { Millán }\end{array}$ & 152,9 & 659 & 4,3 & 26,6 & 12,2 & 9,4 & 51,8 \\
\hline $\begin{array}{l}\text { Casas de } \\
\text { Miravete }\end{array}$ & 50,2 & 157 & 3,1 & 8,0 & 0,0 & 12,0 & 80,0 \\
\hline Casatejada & 111,8 & 1.459 & 13,0 & 32,8 & 14,7 & 10,7 & 41,7 \\
\hline Deleitosa & 144,2 & 790 & 5,5 & 19,1 & 14,1 & 10,8 & 56,0 \\
\hline Higuera & 40,5 & 114 & 2,8 & 43,8 & 6,3 & 12,5 & 37,5 \\
\hline Jaraicejo & 177,5 & 535 & 3,0 & 27,1 & 3,9 & 11,6 & 57,4 \\
\hline $\begin{array}{l}\text { Malpartida } \\
\text { de Plasencia }\end{array}$ & 372,7 & 4.725 & 12,7 & 10,6 & 18,7 & 13,9 & 56,9 \\
\hline Mirabel & 49,3 & 691 & 14,0 & 24,3 & 22,2 & 4,3 & 49,2 \\
\hline Romangordo & 39,1 & 257 & 6,6 & 9,4 & 3,1 & 6,3 & 81,3 \\
\hline Saucedilla & 60,4 & 825 & 13,7 & 30,4 & 15,2 & 7,8 & 46,6 \\
\hline Serradilla & 259,2 & 1.637 & 6,3 & 30,7 & 4,9 & 9,6 & 54,9 \\
\hline Serrejón & 124,2 & 459 & 3,7 & 41,4 & 7,9 & 5,3 & 45,4 \\
\hline Toril & 149,8 & 189 & 1,3 & 60,0 & 5,7 & 0,0 & 34,3 \\
\hline $\begin{array}{l}\text { Torrejón el } \\
\text { Rubio }\end{array}$ & 221,9 & 625 & 2,8 & 39,0 & 6,4 & 8,0 & 46,5 \\
\hline Totales & 1953,5 & 13122 & 6,7 & 23,3 & 13,7 & 10,7 & 52,4 \\
\hline
\end{tabular}

Fuente: INE e Instituto de Estadística de Extremadura.

Entre esos ecosistemas cabe citar el roquedo que aúna el interés geomorfológico que conforman los grandes farallones cuarcíticos del denominado Sinforme de Monfragüe, ejemplo espectacular de relieve apalachense por donde discurren los ríos Tajo y Tiétar que se encajan y cortan las crestas cuarcíticas dando lugar a las llamadas «portillas», siendo la más conocida la denominada «Salto del Gitano».

En segundo lugar, el ecosistema de riberas y masas de agua destaca por su amplia presencia espacial, de tal manera que la configuración de los ríos Tajo y Tiétar (EsteOeste) hacen que este tipo de ecosistema esté muy bien representado en la zona central de Monfragüe, ligados a la existencia de los embalses de Alcántara, Torrejón-Tajo y 
Torrejón-Tiétar. La presencia constante del agua introduce un nuevo factor que aumenta la biodiversidad paisajística albergando infinidad de especies (peces, aves acuáticas, etc.).

En tercer lugar, hemos de referirnos al ecosistema de bosque y matorral mediterráneos que, gracias a la especial configuración del relieve, encierra unos marcados contrastes entre solanas y umbrías. Es así como las vertientes orientadas al norte presentan un bosque mediterráneo mejor conservado, con presencia de alcornoques, quejigos y madroños, mientras que en las solanas predomina la encina y el acebuche. En general, por su carácter impenetrable, las «manchas» se convierten en refugio de una importante, rica y variada fauna (buitre negro, águila imperial, búho real, ciervo, etc.).

En cuarto y último lugar, destaca el ecosistema dehesa que, en el conjunto de la Reserva de la Biosfera de Monfragüe, alcanza las 65.280 ha, siendo el más claro ejemplo del equilibrio entre la intervención humana sobre los recursos naturales y el mantenimiento en un alto grado de las condiciones naturales y de la biodiversidad. Las dehesas de Monfragüe son la clave de un mosaico de aprovechamientos agrícolas, ganaderos, forestales, donde el suelo y el vuelo se constituyen en fuente de riqueza, pero también de aprovechamientos cinegéticos, de áreas de campeo de grandes y medianas rapaces y carroñeras, de cobijo a migratorias procedentes de Centro-Europa o de nidificación de otras aves procedentes de África.

Además, podrían citarse infinidad de ejemplos de su rico patrimonio histórico, caso del Castillo de Mirabel, en origen fue fortaleza del rey Alfonso VIII; el Puente del Cardenal que fue mandado construir por Don Juan de Carvajal, Obispo de Plasencia, y finalizada su obra en 1450; el Castillo de Monfragüe que, por su situación geográfica y ubicación topográfica, ofrece al visitante unas vistas espectaculares del mar de dehesas entre las Tierras de Trujillo al Sur y las Sierras de Gredos al Norte; o, como no, la población de Villarreal de San Carlos, pedanía del municipio de Serradilla, que se constituye como el núcleo más reciente: «se formó esta villa año 1781 por nuestro Catolico Monarca Don Carlos Terzero, que en gloria descanse, y el motivo fue a instancias de la necesidad por ser este sitio un coto de ladrones y malhechores pues en la distancia de puerto a puerto -el de la Serrana y el de las Corchuelas- era un calvario de cruces de las desgracias sucedidas y se iba olvidando esta carretera por el miedo» (Tomás López. Diccionario Geográfico de España, 1798). Villarreal de San Carlos, hasta la próxima construcción del Centro de Visitantes, ha sido y es el área de uso público más importante del Parque Nacional y de la Reserva de la Biosfera. En definitiva, ejemplos todos ellos de ese rico patrimonio histórico y cultural que, además del natural, engloba el territorio objeto de estudio.

\section{OBJETIVOS}

Los resultados que presentamos en este trabajo son los derivados del Proyecto I+D+i «Las áreas de uso público en la Reserva de la Biosfera de Monfragüe. Accesibilidad y capacidad de carga» (Orden MAM 321/2007; No Exp. 024/SGTB/2007 4.1), llevado a cabo por el Grupo de Estudios sobre Desarrollo Rural y Local (GEDERUL) de la Universidad de Extremadura desde 2007 y hasta 2009. 
El objetivo esencial de este trabajo ha sido la realización de un exhaustivo diagnóstico y análisis del turismo en el Parque Nacional y Reserva de la Biosfera de Monfragüe, así como en su área de influencia socioeconómica. Para ello se valoraron, dentro de los siguientes indicadores, las variables que, a continuación, se citan:

1er. Indicador: Perfil del visitante.

- Evolución del número de visitantes (nacionales e internacionales).

- Vinculación socio-profesional del visitante.

- Número de veces que ha visitado este espacio natural.

- Número de personas con las que viaja.

- Grado de conocimiento de los visitantes sobre la Reserva de la Biosfera de Monfragüe.

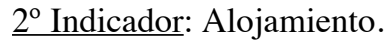

- Localidades de alojamiento.

- Tipología del alojamiento.

- Número medio de pernoctaciones.

- Municipios y entidades de población más visitadas.

- Aportación económica por un producto y/o alojamiento en el Parque Nacional de Monfragüe (sello de calidad).

3er. Indicador: Actividades y/o usos.

- Motivo de la visita a Monfragüe y su entorno.

- Áreas de uso público más visitadas.

- Interés de la visita a las áreas de uso público.

- Fuentes de información utilizadas.

- Calidad y utilidad de la información.

Analizados los valores de estas variables podremos establecer con mayor claridad un modelo en el que interactúen las tres dimensiones del desarrollo sostenible: económica, social y ambiental. Desde el punto de vista económico, el turismo rural/natural se ha tomado en algunos casos como la panacea que salvaguarda las debilitadas economías rurales en determinados territorios, sobre todo en aquellos en los que la dimensión ambiental imponía unas dinámicas territoriales distintas (Vera et al., 2006; Cebrián, 2008).

Sin embargo, a lo largo de este estudio quedará reflejado, en líneas generales, que las interacciones necesarias entre las dimensiones social, económica y ambiental no han funcionado con el dinamismo necesario, habida cuenta de lo que muestran los indicadores.

Es por ello que este planteamiento necesita a priori resolver el dilema de cómo mantener el capital natural sin dejar de considerar el capital económico, al tiempo que el capital social se vea implicado en el desarrollo de su territorio y pueda beneficiarse de las dinámicas del mismo, siempre y cuando la resiliencia de este espacio protegido no se vea afectada negativamente en el tiempo. Y no debiera verse afectada por cuanto que el capital ambiental existente en Monfragüe es un producto social que se ha desarrollado a lo largo de la Historia, mucho antes de hablar de protección de la naturaleza o de políticas de conservación, independientemente de los avatares particulares que llevaron a su declaración como Parque Natural, primero, y Nacional en 2007. 


\section{Cuadro 2 \\ CARACTERÍSTICAS DE LA ENCUESTA}

\begin{tabular}{|l|l|}
\hline Universo & $\begin{array}{l}\text { Visitantes del Parque Nacional de Monfragüe y usuarios de las principales } \\
\text { áreas de uso público }\end{array}$ \\
\hline Ámbito territorial & Parque Nacional y Reserva de la Biosfera de Monfragüe \\
\hline Tamaño de la muestra & 1.829 encuestas \\
\hline Error muestral & $2,2 \%$ \\
\hline Nivel de confianza & $95 \%$ \\
\hline Diseño muestral & Muestreo aleatorio estratificado \\
\hline Trabajo de campo & Agosto de 2008 a Agosto de 2009 \\
\hline
\end{tabular}

Por tanto, aunque el concepto de conservación en sí puede ser contrario a los intereses de las sociedades rurales, no lo es desde el punto de vista más pragmático ya que son las propias sociedades rurales las que, de una $\mathrm{u}$ otra manera, han desarrollado $\mathrm{y}$ han transformado estos espacios protegidos en un producto social. En tal sentido, los conceptos conservación y desarrollo en ningún caso pueden ser considerados como conceptos antagónicos o contradictorios, puesto que es necesaria su compatibilidad para dinamizar los recursos en los territorios rurales (Loscertales, 1999).

\section{MATERIAL Y MÉTODOS}

Para procurar la consecución de los objetivos marcados en el apartado anterior se utilizó una metodología de tipo cuantitativa no experimental, al tiempo que descriptiva y cualitativa analítica, puesto que la finalidad de la investigación era no sólo aportar información completa y exacta de las áreas de uso público, sino que los resultados pudieran contribuir a realizar investigaciones posteriores.

La investigación del turismo (perfil del turista, alojamientos, etc.) en Monfragüe se llevó a cabo utilizando la encuesta de tipo social (Cea D'Ancona, 1998) o muestreo aleatorio, consistente en extraer una muestra de una población finita, sobre un cuestionario diseñado previamente y garantizando la representatividad de la muestra o Universo poblacional en un período de tiempo determinado. El trabajo de campo se llevó a cabo entre agosto de 2008 y agosto de 2009 para una muestra de 1.829 encuestas, sobre una población estimada de 200.374 visitantes potenciales (Centro de Visitantes de Villarreal de San Carlos), un nivel de confianza de1 $95 \%$ y un 2,2\% de margen de error. Asimismo la temporalidad de las encuestas en el período de referencia ha tratado de hacer coincidir el mayor número de encuestas con aquellos meses de mayor afluencia de visitantes (Cuadros 3 y 4).

En segundo lugar, la muestra se obtuvo mediante observaciones de campo, de tal manera que las encuestas fueron realizadas directamente por el equipo técnico contratado con cargo al proyecto. En este sentido, durante la realización de las mismas el equipo cuantificaba el número de usuarios que se encontraba en el área de uso público para obtener una variable objetiva de observación, como es la obtención de los valores máximos y mínimos de carga durante el período de estudio para más tarde facilitar un análisis estadístico detallado. 


\section{Cuadro 3 \\ NÚMERO DE ENCUESTAS POR ÁREA DE USO PÚBLICO}

\begin{tabular}{|l|r|}
\hline \multicolumn{1}{|c|}{ Área de Uso Público } & \multicolumn{1}{c|}{ N $^{\circ}$} \\
\hline Salto del Gitano & 413 \\
\hline Villarreal de San Carlos & 369 \\
\hline Castillo de Monfragüe & 357 \\
\hline Tajadilla & 237 \\
\hline Portilla del Tiétar & 153 \\
\hline Itinerario Rojo & 163 \\
\hline Itinerario Verde & 73 \\
\hline Itinerario Amarillo & 64 \\
\hline Total & 1.829 \\
\hline
\end{tabular}

Fuente: Elaboración propia.

\section{Cuadro 4}

TEMPORALIDAD DE LAS ENCUESTAS

\begin{tabular}{|l|r|r|r|}
\hline \multicolumn{1}{|c|}{ Meses } & \multicolumn{2}{c|}{ Número } & \multicolumn{2}{c|}{ Porcentaje } & \multicolumn{2}{c|}{ \% Visitas (*) } \\
\hline Agosto (2008) & 230 & 12,6 & 6,3 \\
\hline Septiembre (2008) & 102 & 5,6 & 9,8 \\
\hline Octubre (2008) & 150 & 8,2 & 5,2 \\
\hline Noviembre (2008) & 106 & 5,8 & 4,3 \\
\hline Diciembre (2008) & 42 & 2,3 & 2,1 \\
\hline Enero (2009) & 19 & 1,0 & 4,0 \\
\hline Febrero (2009) & 41 & 2,2 & 14,2 \\
\hline Marzo (2009) & 321 & 17,6 & 21,9 \\
\hline Abril (2009) & 430 & 23,5 & 14,1 \\
\hline Mayo (2009) & 201 & 11,0 & 5,8 \\
\hline Junio (2009) & 85 & 4,6 & 4,3 \\
\hline Julio (2009) & 102 & 5,6 & 100,0 \\
\hline Total & 1.829 & 100,0 & \\
\hline
\end{tabular}

(*) Porcentaje medio de visitas mensuales en el período 1994-2012.

Fuente: Elaboración propia. 
En tercer lugar, la muestra está perfectamente estructurada, esto es, la encuesta constaba de 32 preguntas y se diseñó según los modelos propuestos por EUROPARC. Las variables del cuestionario han versado sobre el espacio natural protegido (modelo de uso público), el perfil del visitante (actitudes, costumbres y conocimientos) y las valoraciones de éstos sobre los equipamientos y las áreas de uso público (Anexo 1). Todo ello para poder agrupar, evaluar, cuantificar y relacionar los resultados posteriormente, al tiempo que valorar su incidencia e interrelación (Sabino, 1992).

\section{RESULTADOS Y DISCUSIÓN}

\subsection{Perfil de los visitantes encuestados}

\subsubsection{Evolución del número de visitantes}

La dinámica que marca la evolución del número de visitantes tiene un antes y un después del año 2007. En este año se alcanzó la mayor afluencia de visitantes registrados en el Centro de Información del Parque (83.819 visitantes), justo el año en que Monfragüe es declarado Parque Nacional (Ley 1/2007, de 2 de marzo), al tiempo que los muestreos realizados por la Dirección del Parque arrojaron 317.590 visitas dicho año (se trata de una aproximación al número real de visitantes, independientemente de su paso o no por los Centros de Información y/o Visitantes).

A partir de esa fecha y hasta la actualidad es probable que los efectos de la crisis económica también hayan afectado de manera sensible al número de visitantes/año, viéndose reducido el total desde 2007 hasta 2012 en 18.311 visitantes; año en el que, según datos de la Dirección General de Medio Ambiente del Gobierno de Extremadura, acudieron a Monfragüe un total de 65.508 visitantes (Figura 2). En todo caso, la dinámica del turismo hacia el conjunto de los espacios naturales protegidos de Extremadura ha seguido una dinámica parecida a la de Monfragüe, esto es, un incremento constante desde 2003 (189.846 visitantes) hasta 2008 (301.748 visitantes), para después entrar en una etapa recesiva hasta 2012 (191.533 visitantes).

Atendiendo a la procedencia de los encuestados, los resultados permiten comprobar que el 90,3\% de los visitantes son de origen nacional, mientras que sólo el 9,7\% proceden de países extranjeros, cifra similar a la registrada en el Centro de Visitantes del Parque entre 1994 y $2012(9,16 \%)$.

A nivel nacional, las encuestas aclaran que el 26,8\% de los visitantes procede de la propia Comunidad Autónoma de Extremadura, seguida de la Comunidad de Madrid con un 25,9\%, más lejos se sitúan las comunidades de Valencia, Andalucía, Cataluña, Castilla y León, País Vasco y Castilla la Mancha.

En este caso, merece destacarse que una cuarta parte de los visitantes encuestados proceden de Madrid. Sin duda, la proximidad geográfica es un factor decisivo para explicar la afluencia de visitantes madrileños a Monfragüe, pues el tiempo invertido en el desplazamiento, si este se realiza en automóvil, se sitúa en torno a las dos horas y media. No obstante, debe reseñarse que esta distancia es similar en el caso de Andalucía y Castilla y León, aunque, como puede apreciarse, los resultados son claramente distintos (Cuadro 5) 
Figura 2

VISITANTES CONTABILIZADOS EN EL CENTRO DE VISITANTES (1994-2012)

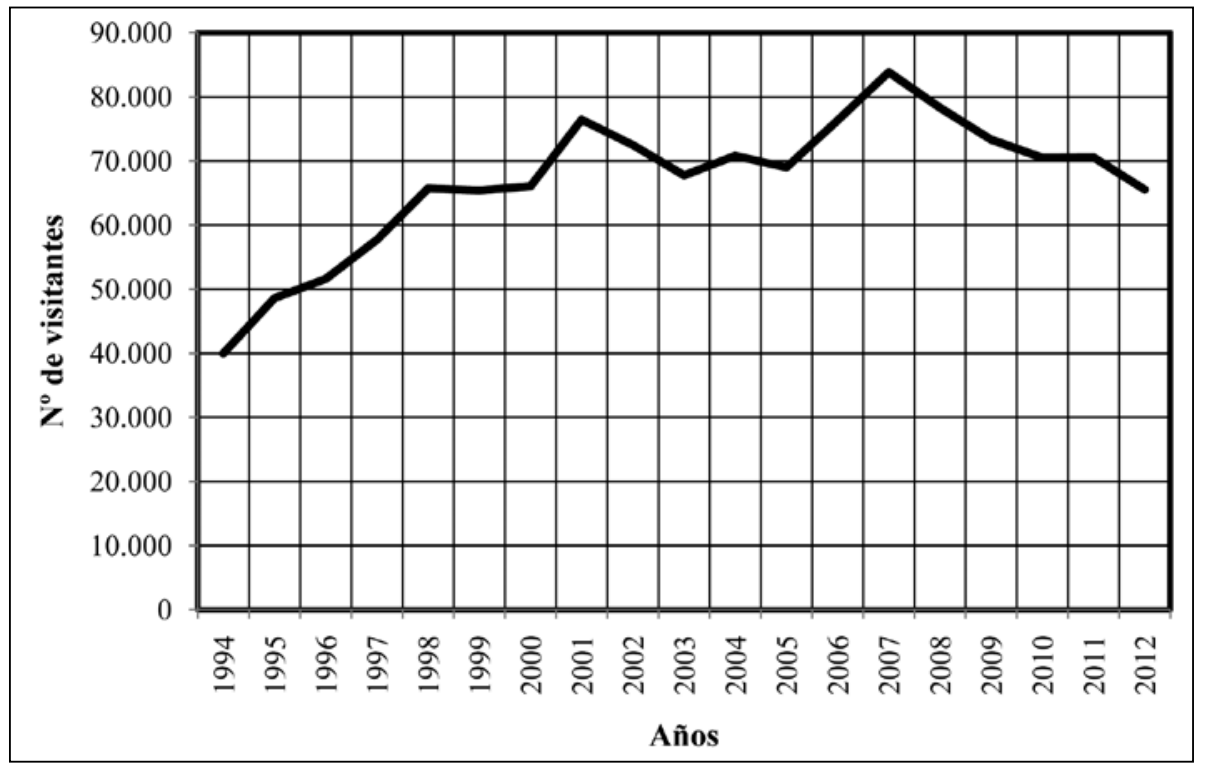

Fuente: Parque Nacional de Monfragüe y Dirección General de Medio Ambiente (Gobierno de Extremadura)

y evidencian el peso de otros múltiples factores que van desde el tamaño de las ciudades de procedencia a la posibilidad de visitar otros enclaves más próximos.

En otro orden de aspectos, debe señalarse que la afluencia de visitantes al Parque se caracteriza por una sensible estacionalidad. Algo más de la mitad de las visitas suelen concentrarse en primavera $(50,2 \%)$, circunstancia ésta que encuentra explicación no sólo en el especial atractivo que ofrecen la flora y la fauna en esta estación, sino también en los períodos vacacionales de Semana Santa y Puente de Mayo que, obviamente, facilitan la presencia de turistas y la prolongación de la estancia (Ver Cuadro 4).

\subsubsection{Vinculación socio-profesional del visitante}

Uno de los aspectos más destacados de la encuesta fue el referido al perfil-socioprofesional de los encuestados. El resultado ha sido revelador en el sentido de que casi una tercera parte de los mismos pertenece al sector servicios (31\%), seguido del sector educativo $(24,4 \%)$, y muy de cerca por los profesionales ligados a la Administración $(17,9 \%)$. Ha de destacarse, paralelamente, que en los sondeos realizados muy pocos de los encuestados tenían una profesión vinculada directamente al sector agrario.

Estos datos podrían interpretarse desde una doble perspectiva. Por un lado, podría argumentarse la mayor disponibilidad de tiempo libre de los trabajadores relacionados con aquellos sectores socio-profesionales y, por otro lado, el mayor interés de éstos por la Naturaleza, o por ambas posibilidades al mismo tiempo. Como es obvio, los agricultores 


\section{Cuadro 5 \\ DISTRIBUCIÓN DE LOS VISITANTES SEGÚN COMUNIDAD \\ AUTÓNOMA DE PROCEDENCIA}

\begin{tabular}{|l|r|}
\hline Comunidad Autónoma & Porcentaje \\
\hline Extremadura & 26,84 \\
\hline Madrid & 25,90 \\
\hline Valencia & 7,38 \\
\hline Andalucía & 7,00 \\
\hline Cataluña & 6,90 \\
\hline Castilla y León & 6,00 \\
\hline País Vasco & 4,60 \\
\hline Castilla-La Mancha & 4,40 \\
\hline Galicia & 4,20 \\
\hline Aragón & 1,20 \\
\hline Asturias & 1,03 \\
\hline Murcia & 1,03 \\
\hline Baleares & 1,00 \\
\hline Canarias & 1,00 \\
\hline Cantabria & 0,70 \\
\hline Navarra & 0,60 \\
\hline La Rioja & 0,22 \\
\hline Total & 100,00 \\
\hline
\end{tabular}

Fuente: Elaboración propia.

y ganaderos, cuya actividad se desarrolla las más de las veces en contacto directo con la naturaleza, manifiestan mayor interés por otras opciones turísticas.

Igualmente, los datos obtenidos muestran también un participación alta en el grupo de la educación $(24,4 \%$ de los encuestados). Ello se debe a la sensibilización por la naturaleza y los temas de educación ambiental promovidos tanto por los centros docentes (colegios, centros de educación secundaria, universidad, etc.) como por el propio Parque Nacional.

Por otro lado, encontramos que un $10 \%$ de los encuestados son jubilados que eligen completar de un modo efectivo su tiempo de ocio con la visita al Parque Nacional de Monfragüe (Cuadro 6). 


\section{Cuadro 6 \\ PERFIL SOCIO-PROFESIONAL DE LOS ENCUESTADOS}

\begin{tabular}{|l|r|}
\hline Perfil & Porcentaje \\
\hline Sector Servicios & 31,0 \\
\hline Educación & 24,4 \\
\hline Administración & 17,9 \\
\hline Jubilados/Prejubilados & 10,0 \\
\hline Sector Industrial & 6,4 \\
\hline Amas de Casa & 5,4 \\
\hline Desempleados & 3,1 \\
\hline Sector Agrario & 1,8 \\
\hline Total & 100,0 \\
\hline
\end{tabular}

Fuente: Elaboración propia.

\subsubsection{Número de veces que ha visitado este espacio natural}

Una de los aspectos más interesantes y significativos del turismo, en general, y sobre todo del turismo rural, es el de la fidelidad del usuario (Cánoves et al, 2004). Esta es la razón que explica el enunciado de este apartado y la correspondiente pregunta en el cuestionario.

Los resultados de la encuesta reflejan, en este sentido, que el 57\% de los visitantes llegaban por primera vez al Parque. No obstante, lo realmente importante es que aquellos encuestados que lo habían visitado en más de una ocasión sumaban el $43 \%$ restante (Cuadro 7). Sin duda alguna, se trata de un dato enormemente significativo en lo que a la fidelización del usuario se refiere, ya que ésta se percibe como la consolidación de la relación entre la actitud propia de una persona y el hecho de repetir como cliente (Jafari, 2000; Dick y Basu, 1994; Gremler y Brown, 1996).

Cuadro 7

NÚMERO DE VECES QUE VISITA MONFRAGÜE

\begin{tabular}{|l|r|}
\hline Número & Porcentaje \\
\hline Primera vez & 57,0 \\
\hline De 2 a 5 veces & 27,3 \\
\hline Más de 5 veces & 15,7 \\
\hline Total & 100,0 \\
\hline
\end{tabular}

Fuente: Elaboración propia. 


\subsubsection{Número de personas con las que viaja}

Un referente más en la encuesta fue el indicador sobre el número de personas con las que se viaja. De este modo, los resultados arrojaron que un 77,2\% de los mismos viaja en grupos de menos de 5 personas, y que el 7,1\% viajan en grupos de entre 2 y 10 personas, mientras que el $15,7 \%$ viaja en grupos de mas de 10 personas. Estos datos proyectan dos hechos muy importantes: por un lado, que la mayoría se desplaza en vehículos particulares y grupos pequeños (menos de 5 personas) y, por otro lado, que los grupos de más de 10 personas suelen utilizar vehículos de transporte colectivos (autobuses).

Por tanto, se puede intuir que, por un lado, los costes de viaje son un parámetro esencial en la medida en que la mayor parte de los encuestados viaje en grupos reducidos (menos de 5 personas) y en vehículos particulares (Figura 3). Y, por otro lado, no deja de ser un valor añadido por cuanto que el turismo en grupos reducidos favorece en todo caso el desarrollo sostenible y la propia gestión que la Administración u órgano gestor del Parque Nacional pueda llevar a cabo hacia los visitantes. En este sentido, la propia Carta Europea de Turismo Sostenible en los Espacios Protegidos (2007-2010), insiste en que una de las premisas para reforzar el grado de satisfacción del visitante es el fomento de la participación del turismo en pequeños grupos. Luego, vistos los resultados de las encuestas, sería positivo que, tanto los órganos de gestión del Parque como las propias empresas turísticas, insistieran en esa línea.

Figura 3

NÚMERO DE PERSONAS CON LAS QUE VIAJA

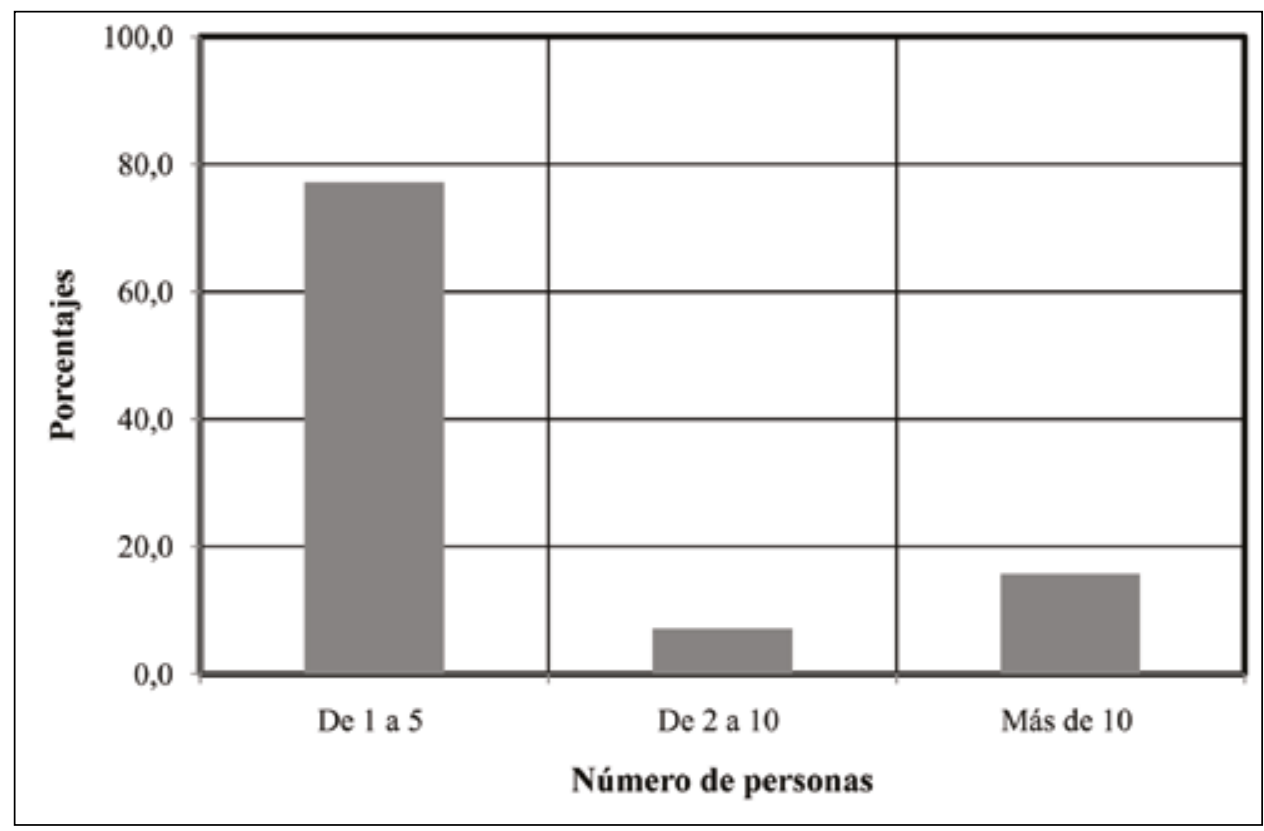

Fuente: Elaboración propia. 


\subsubsection{Grado de conocimiento de los visitantes sobre el Parque Nacional y Reserva de la Biosfera de Monfragüe}

En líneas generales, gracias a la cada vez más estrecha relación entre la sociedad y los espacios naturales (Maurín, 2005-2008), el grado de percepción y el nivel de conocimiento que muestra ésta en la actualidad es cada vez mayor. Prueba de ello es que una media del $66 \%$ de los encuestados tiene conocimiento de lo que es un Parque Nacional, lo que da idea de que el incremento del turismo de naturaleza se está afianzando entre los valores culturales de la sociedad.

Como se aprecia en el Cuadro 8, existen marcadas diferencias entre, por ejemplo, el sector educativo, que con un 78,6\% presenta el nivel más alto de conocimiento sobre lo que es un Parque Nacional, y los encuestados pertenecientes al sector agrario, que tienen menor grado de conocimiento sobre el particular.

\section{Cuadro 8}

CONOCIMIENTO DE LOS VISITANTES SOBRE EL PARQUE NACIONAL Y RESERVA DE LA BIOSFERA DE MONFRAGÜE

\begin{tabular}{|l|r|r|r|}
\hline \multicolumn{1}{|c|}{ Perfiles socio-profesionales } & \multicolumn{1}{c|}{ Sabe (\%) } & No sabe (\%) & \multicolumn{1}{c|}{ NS/NC (\%) } \\
\hline Sector Servicios & 66,2 & 31,3 & 2,5 \\
\hline Educación & 78,6 & 18,7 & 2,7 \\
\hline Administración & 68,0 & 30,8 & 1,2 \\
\hline Jubilados/Prejubilados & 67,2 & 31,1 & 1,7 \\
\hline Sector Industrial & 68,4 & 29,9 & 1,7 \\
\hline Amas de Casa & 55,6 & 42,4 & 2,0 \\
\hline Desempleados & 66,7 & 31,6 & 1,7 \\
\hline Sector Agrario & 55,9 & 38,2 & 5,9 \\
\hline
\end{tabular}

Fuente: Elaboración propia.

Probablemente, esta variedad de situaciones debiera de guiar la promoción y divulgación turística de la zona por parte de los responsables del parque, toda vez que un mayor conocimiento de este territorio, tanto de su patrimonio ambiental como cultural, podrá jugar a favor de una mayor afluencia de visitantes y, en consecuencia, de una dinamización de la actividad turística.

\subsection{Alojamiento}

\subsubsection{Localidades de alojamiento}

Una amplia mayoría de los visitantes $(65,5 \%)$ ha respondido en la encuesta que no se aloja en ninguna de las poblaciones del Parque ni tampoco en su área de influencia 
socioeconómica. La razones que pueden explicar este dato son diversas, sin embargo ninguna de ellas obedece a la existencia de una escasa oferta hotelera y alojativa rural en la zona, ya que en el territorio de estudio hay una abundante y diversa oferta hotelera (7 apartamentos rurales, 17 casas rurales, 7 hoteles rurales, 1 hospedería, 1 camping y 2 albergues que, en conjunto, ofertan cerca de 650 plazas) (Fuente: Red Extremeña de Desarrollo Rural). De otro lado, una buena parte de los encuestados procede de Extremadura $(26,84 \%)$ y, finalmente, la cercanía de tres vértices urbanos atractivos y atrayentes (Trujillo, Plasencia y Cáceres) que, con su oferta hotelera, acaparan la demanda de la mayor parte de los usuarios del Parque.

Los municipios y/o entidades de población del Parque que el usuario elige con una mayor frecuencia para su alojamiento son Malpartida de Plasencia $(11,5 \%)$, Villarreal de San Carlos $(10,3 \%)$ y Torrejón el Rubio $(8,8 \%)$. El resto de los municipios presentan valores muy bajos, no alcanzando siquiera el $1 \%$, y reflejando una disimetría que puede redundar en perjuicio de una adecuada identificación de la población con la figura del parque y un menoscabo de las potencialidades que tal identificación podría representar en el capital social en dicho territorio (Cuadro 9).

\section{Cuadro 9 \\ LOCALIDADES DE ALOJAMIENTO PREFERIDAS POR LOS USUARIOS DE MONFRAGÜE}

\begin{tabular}{|l|r|r|}
\hline \multicolumn{1}{|c|}{ Localidades } & \multicolumn{1}{c|}{ N $^{\text {Encuestados }}$} & \multicolumn{2}{c|}{ Porcentaje } \\
\hline Malpartida de Plasencia & 210 & 11,5 \\
\hline Villarreal de San Carlos & 188 & 10,3 \\
\hline Torrejón el Rubio & 161 & 8,8 \\
\hline Serrejón & 16 & 0,9 \\
\hline Serradilla & 14 & 0,8 \\
\hline Toril & 9 & 0,5 \\
\hline Subtotal Parque Nacional & 598 & 32,7 \\
\hline Subtotal Área de Influencia Socio. & 33 & 1,8 \\
\hline Otros destinos fuera del Parque & 1.198 & 65,5 \\
\hline Total & 1.829 & 100,0 \\
\hline
\end{tabular}

Fuente: Elaboración propia.

\subsubsection{Tipología del alojamiento}

En lo referente al tipo de alojamiento elegido por el usuario de Monfragüe, se obtuvo que el $24,8 \%$ de los visitantes encuestados se alojaban en su domicilio habitual. Este dato, como bien cabía esperar, está directamente relacionado con la procedencia de los visitantes ya que, como se indicó anteriormente, casi el $27 \%$ procedía de la propia Comunidad Autónoma de Extremadura. 
Por otro lado, los datos señalan que un 14,4\% se alojó en domicilios de familiares, y que el 9,9\% elige como alojamiento el camping. De todos ellos, un 17,3\% de visitantes ha dicho que se aloja en hoteles y un 15,3\% tomó la opción de la casa rural. Sin embargo, en su conjunto, como señalábamos en el apartado anterior, hay una gran mayoría que, independientemente del tipo de alojamiento, elige lugares fuera del Parque y su área de influencia socioeconómica (Cuadro 10).

Cuadro 10

MODALIDADES DE ALOJAMIENTO PREFERIDAS POR LOS USUARIOS DE MONFRAGÜE

\begin{tabular}{|l|r|r|r|}
\hline Tipo de alojamiento & Fuera AIS (\%) & Dentro AIS (\%) & \multicolumn{1}{|c|}{ Subtotal (\%) } \\
\hline Domicilio Habitual & 22,8 & 1,9 & 24,8 \\
\hline Hotel & 13,0 & 4,3 & 17,3 \\
\hline Casa Rural & 6,5 & 8,8 & 15,3 \\
\hline Alojamiento Familiar & 11,8 & 2,6 & 9,9 \\
\hline Camping & 2,4 & 7,5 & 3,7 \\
\hline Hostal & 3,1 & 0,7 & 14,6 \\
\hline Otros & 6,2 & 8,4 & 100,0 \\
\hline Total & 65,7 & 34,3 & \\
\hline
\end{tabular}

(Fuera o dentro del Área de Influencia Socioeconómica del Parque).

Fuente: Elaboración propia.

\subsubsection{Número medio de pernoctaciones}

Un dato importante es el referente al número medio de pernoctaciones, resultando que el $43,9 \%$ de los encuestados lleva a cabo una estancia de entre 2 y 5 noches. La estancia media en Extremadura en alojamientos turísticos rurales ascendió en 2013 a 2,28 pernoctaciones (Encuesta de Ocupación en Alojamiento Turísticos. INE, 2013), en el caso de la provincia cacereña ese valor sube hasta las 2,32 pernoctaciones, cifras muy superiores a la estancia media en alojamientos turísticos en Extremadura que sólo alcanzó el valor de 1,71 pernoctaciones. En todo caso, el grado de ocupación por plazas en alojamientos turísticos rurales en 2013 sólo alcanzó el 11,25\%. Estas cifras indican que el turismo rural en el territorio de Monfragüe se mueve en los mismos valores que el turismo rural en Extremadura o en la provincia de Cáceres, aunque lejos de los valores de algunas de las Comunidades Autónomas de referencia en el sector (Andalucía 3,45 pernoctaciones de media o Baleares 4,46 por citar algunos ejemplos).

Por tanto, que el 43,9\% de los usuarios encuestados pernocte entre 2 y 5 noches es un dato ciertamente positivo. Lo sería más para el área de influencia socioeconómica de Monfragüe si la mayor parte de las mismas fueran realizadas allí ya que cuenta con suficiente oferta hotelera y alojativa como citábamos anteriormente. Pero, como veíamos antes, la realidad es otra muy distinta. Muchas de las posibilidades de desarrollo local 
basadas en la complementariedad del recurso turístico se marchan fuera por la inacción o incapacidad local para asimilar la demanda turística, o por la elección del visitante de otros destinos más atractivos para alojarse.

Por otro lado, el $8 \%$ realiza una estancia de una noche o simplemente se acerca a pasar el día $(31 \%)$, en correspondencia con la mayor procedencia regional de visitantes. Es de destacar, en cualquier caso, que un $17,1 \%$ de los encuestados realizan una estancia superior a 5 noches, un dato muy importante que indica que en los últimos años el turismo rural en España y, en nuestro caso, en Extremadura ha experimentado un gran crecimiento, aunque todavía lejos de convertirse en una alternativa de renta complementaria, sólida y duradera en el tiempo (Cuadro 11).

\section{Cuadro 11 \\ PERNOCTACIONES MEDIAS REALIZADAS POR LOS USUARIOS DE MONFRAGÜE}

\begin{tabular}{|l|r|}
\hline \multicolumn{1}{|c|}{ Número } & \multicolumn{1}{c|}{ Porcentaje } \\
\hline Pasar el día & 31,0 \\
\hline 1 noche & 8,0 \\
\hline 2 a 5 noches & 43,9 \\
\hline Más de 5 noches & 17,1 \\
\hline Total & 100,0 \\
\hline
\end{tabular}

Fuente: Elaboración propia.

\subsubsection{Municipios y entidades de población más visitadas}

Respecto a las localidades que dicen haber conocido los visitantes, los datos arrojan que el 32,7\% de éstos ha visitado Villarreal de San Carlos, la única entidad de población que se encuentra dentro del Parque Nacional del Monfragüe y aquella que, hasta la fecha, aglutina todos los Centros de Información e Interpretación del mismo. El segundo lugar lo ocupa Torrejón el Rubio $(13,6 \%)$ y, en tercer lugar, Malpartida de Plasencia $(10,9 \%)$. El resto de núcleos de población son mucho menos visitados por los usuarios, luego es necesario en este sentido establecer nuevas rutas, itinerarios, miradores, etc., en definitiva nuevas áreas de uso público más y mejor distribuidas por el Parque no sólo para ampliar la oferta al visitante, sino para favorecer que el desarrollo sea equitativo y solidario entre todos los municipios del área de influencia socioeconómica del Parque.

En todo caso, los usuarios de Monfragüe, además de conocer el Parque Nacional, han visitado ciudades cercanas como Plasencia (34,7\%), Cáceres (29\%) o Trujillo (29\%); ciudades que, como señalábamos antes, quizás sean las elegidas para su alojamiento.

\subsubsection{Aportación económica por un producto y/o alojamiento en el Parque Nacional de Monfragüe ( sello de calidad)}

La concesión de la Carta Europea del Turismo Sostenible en Espacios Naturales Protegidos (CETS) en septiembre de 2011 a Monfragüe es el garante de un nivel de calidad 
óptimo en el uso público, esto es, en mejorar los servicios, las instalaciones e infraestructuras, así como su gestión, al tiempo que todo ello se realice de forma compatible y consensuada con los principales objetivos del Parque, que no son otros que la protección y conservación del territorio. Por ello, la marca de calidad turística es un sello de garantía y valedor del producto que se ofrece al usuario (Pillet, 2008).

Es así, que en las encuestas realizadas los usuarios se han mostrado dispuestos a pagar más por un producto obtenido en el espacio natural protegido $(69,2 \%)$, así como también a pagar más por un alojamiento en dicho espacio $(56,6 \%)$. Estos datos ponen de relieve que la sociedad actual cada día aprecia y valora más lo que representan los espacios naturales protegidos y los productos que ofertan.

\subsection{Actividades y/o usos}

\subsubsection{Motivo de la visita a Monfragüe y su entorno}

Resulta interesante comprobar que uno de cada dos encuestados visita Monfragüe para conocer el Parque Nacional, mientras que sólo un 6,7\% lo hace para visitar la Reserva de la Biosfera. Sin duda, la razón estriba en que esta última constituye una figura menos conocida entre la población, por lo que se hace necesario trasladar una mayor información sobre la misma al conjunto de la población, sobre todo a la propia población local, y una mayor difusión de los atractivos paisajísticos, artísticos y culturales de este entorno (Cuadro 12). Hemos de insistir, una vez más, en la necesidad de hacer visibles al conjunto de la población de la zona, las ventajas de residir en un espacio protegido, pues de otro modo se significarán los posibles inconvenientes que pudieran derivarse de tal protección sobre los usos tradicionales del territorio. La presencia de turistas y su aportación a la economía de los distintos municipios, puede contribuir decisivamente a la consecución de tales objetivos.

\section{Cuadro 12}

\section{MOTIVACIÓN DE LA VISITA A MONFRAGÜE}

\begin{tabular}{|l|r|}
\hline Motivo & Porcentaje \\
\hline Conocer el PNM & 50,2 \\
\hline Conocer Extremadura & 24,3 \\
\hline Conocer la RBM & 6,7 \\
\hline Otros & 18,8 \\
\hline Total & 100,0 \\
\hline
\end{tabular}

Fuente: Elaboración propia.

\subsection{2. Áreas de uso público más visitadas}

Las áreas de uso público más visitadas por los encuestados han sido el Centro de Información de Villarreal de San Carlos $(32,3 \%)$, el Castillo de Monfragüe $(32,1 \%)$ y el Centro de Interpretación de Villarreal de San Carlos $(29,4 \%)$. En la encuesta no se preguntó por 
el Salto del Gitano por ser el área de uso público más visitada y emblemática del Parque Nacional, en cambio si se preguntó por otras áreas de uso público interesantes y alejadas de los circuitos turísticos tradicionales dentro del Parque, como el Castillo de Mirabel o el Museo de Serradilla (Cuadro 13).

\section{Cuadro 13 \\ ÁREAS DE USO PÚBLICO MÁS VISITADAS EN MONFRAGÜE}

\begin{tabular}{|l|r|}
\hline Áreas de uso público & Porcentaje \\
\hline Centro de Información & 32,3 \\
\hline Castillo de Monfragüe & 32,1 \\
\hline Centro de Interpretación & 29,4 \\
\hline Castillo de Mirabel & 3,4 \\
\hline Museo de Serradilla & 2,8 \\
\hline Total & 100,0 \\
\hline
\end{tabular}

Fuente: Elaboración propia.

\subsubsection{Interés de la visita a las áreas de uso público}

Los visitantes encuestados centran su interés en la visita a las áreas de uso público más conocidas (Castillo de Monfragüe, Salto del Gitano, Tajadilla o Portilla del Tiétar) por motivos turísticos $(38,7 \%)$ y ornitológicos $(26 \%)$. Podemos destacar el interés que el turismo ornitológico ha experimentado en los últimos años. En la actualidad nos encontramos ante un mercado turístico altamente especializado, donde el entorno natural y sus recursos se han convertido en el telón de fondo para multitud de actividades de ocio, prueba de ello es la Feria Internacional de Ornitología que se celebra anualmente en Villarreal de San Carlos, pese a que durante los días de celebración de la misma se sobrepase puntualmente la capacidad de carga de esta área de uso público.

\subsubsection{Fuentes de información utilizadas}

Las fuentes utilizadas por los visitantes para obtener una información previa a su visita a Monfragüe son muy variadas. No obstante, es significativa la aportación del Centro de Información de Villarreal de San Carlos, ya que el $72 \%$ de los encuestados señala que éste es la principal fuente de información a su llegada. Igualmente observamos resultados sorprendentes, ya que tan solo el 17,5\% y el 3,3\% aseguran haber obtenido información de internet y de guías turísticas respectivamente, generalmente los medios más habituales de uso. Sin duda, estos datos reflejan una deficiente promoción del Parque y la Reserva a través de los que, presumiblemente, debieran ser los medios de mayor alcance y difusión en la actual sociedad de la información.

Sería muy positivo que, desde el Organismo Autónomo de Parques Nacionales en España, se empezase a trabajar en aplicaciones móviles como la Nat Geo Mobile producida por National Geographic que engloba información diversa (estadística básica 
del parque, lugares y tipos de alojamiento, fotos, itinerarios, etc.) sobre los 20 parques nacionales más visitados de EE.UU. En todo caso, ya existe una aplicación web denominada «Parques Nacionales Interactivos» que, desarrollada por el Centro Nacional de Información Geográfica, ofrece una interesante información sobre la historia, los centros de visitantes e información, la fauna y la flora de algunos de los Parques Nacionales de España, entre ellos Monfragüe (http://www.magrama.gob.es/es/red-parques-nacionales/ parques-nacionales-interactivos/).

\subsubsection{Calidad y utilidad de la información}

En cuanto a la calidad y utilidad de la información sobre las rutas es de reseñar que los visitantes encuestados encuentran que los Itinerarios Verde y Amarillo son los que presentan una información menos adecuada y útil para su realización, aunque los resultados arrojan que, en líneas generales, la calidad de la información es adecuada y suficiente, aunque siempre mejorable (Figura 4), sobre todo si tenemos en cuenta los resultados del Estudio sobre la Calidad de la Información Ambiental Autonómica en la Red (2012), realizado por la Asociación de Ciencias Ambientales (ACA), en el que las comunidades autónomas de Cantabria, Islas Baleares, Extremadura, Aragón y Asturias se encuentran entre las que menos información ambiental ofrecen.

\section{Figura 4}

\section{CALIDAD Y UTILIDAD DE LA INFORMACIÓN SOBRE LAS RUTAS DE MONFRAGÜE}

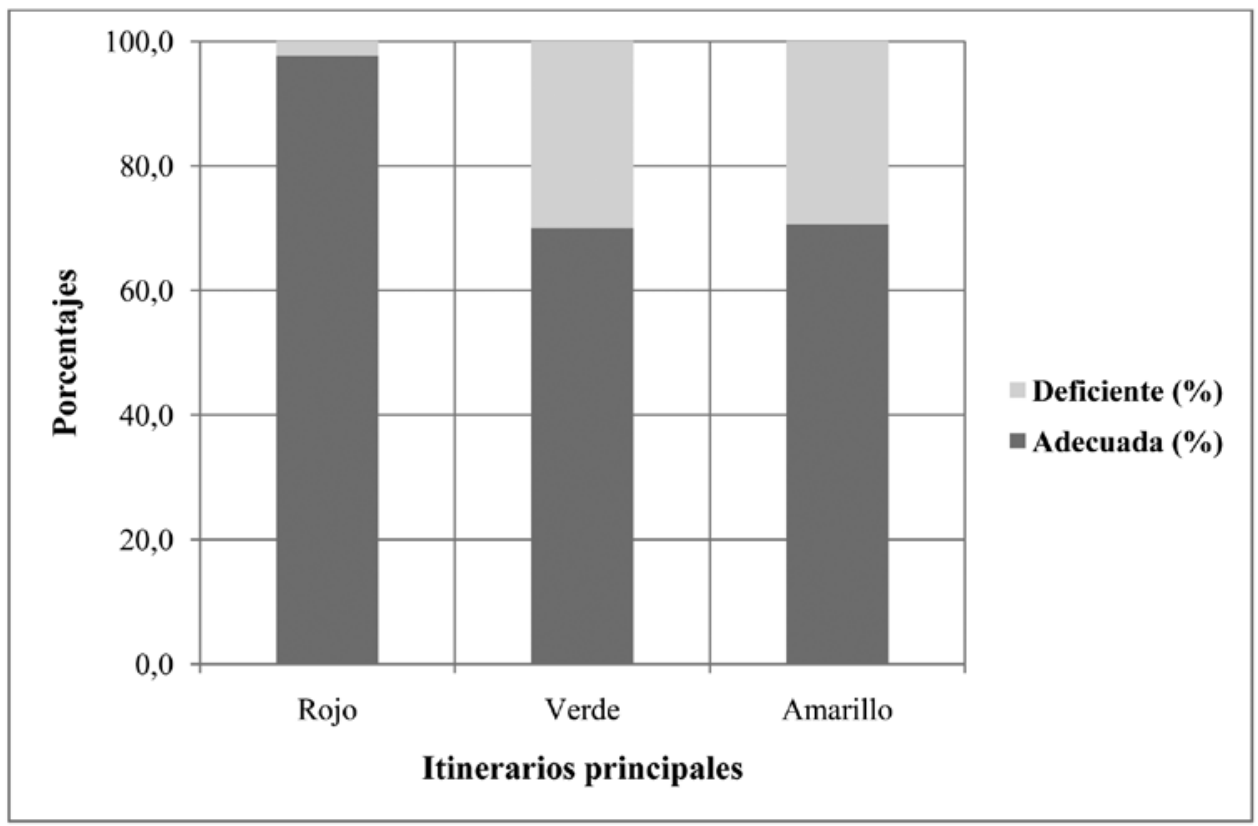

Fuente: Elaboración propia. 


\section{CONCLUSIONES}

Hemos de concluir significando, entre otros aspectos, que Monfragüe presenta una expectativa territorial de desarrollo en la que hasta la fecha prevalecen las sombras sobre las luces. Así lo muestran algunos indicadores como el profundo envejecimiento demográfico, la fuerte dependencia agraria de la economía local o la limitada capacidad de la actividad turística para dinamizar el territorio de una manera permanente.

Sin embargo, lejos de valoraciones más o menos subjetivas sobre las aportaciones socioeconómicas (las ambientales ni son discutibles ni se deben poner en duda) que puede aportar una figura de protección del medio natural sobre el territorio en cuestión, hemos de señalar que la declaración de Monfragüe como Parque Nacional está generando una serie de oportunidades para los municipios que integran este espacio protegido, pese a lo relativamente reciente de su declaración.

Es así como, pese a la desestructuración social que presenta, aunque este hecho sea inherente a todas las sociedades rurales debilitadas desde el punto de vista económico y demográfico, Monfragüe muestra un Índice de Envejecimiento del 188\% frente al $202 \%$ de media que presentan otros territorios rurales extremeños de penillanura que no cuentan con superficies protegidas. No es menos cierto, no obstante, que el valor añadido que generen los recursos naturales, ambientales y paisajísticos de este territorio, puedan constituir un acicate para la diversificación económica de la zona y un motivo de esperanza para su devenir socioeconómico.

En este sentido, teniendo en cuenta los resultados mostrados en los apartados anteriores y concernientes al perfil del encuestado, sus preferencias en el tipo o lugares de alojamiento, o respecto a las actividades que desarrolla, se destacan las siguientes fortalezas y oportunidades de este espacio protegido:

Fortalezas:

- Referente de patrimonio natural en el ámbito mediterráneo.

- Valorización personal y elevada componente afectiva de los usuarios hacia el territorio del Parque.

- Actitud positiva del usuario hacia la marca «Monfragüe», así como a los productos y/o servicios que le conducen a repetir su visita (fidelidad).

- La sociedad de Monfragüe presenta unos valores de confianza bastante altos por las instituciones y por la capacidad de sus ciudadanos, al tiempo que, desde la expectativa territorial (Hardin, 1999 y 2001; Buendía y Somuano, 2003), se ha observado que esta comunidad confía plenamente en el futuro de su territorio (Leco, 2012).

Oportunidades:

- Aumentar la difusión del Parque en dos niveles: territorial (incrementar las visitas, sobre todo de extranjeros, mediante el marketing turístico apoyado en las nuevas tecnologías de la información y la comunicación) y social (diversificar la oferta hacia sectores como jubilados, personas con diversidad funcional,.., generalmente con mayor poder adquisitivo $\mathrm{y}$, sobre todo, con mayor disponibilidad de tiempo libre). 
- Fomentar una política de marketing turístico mucho más incisiva (público-privada), al tiempo que empiecen a implantarse otro tipo de empresas ligadas al desarrollo de actividades turísticas en el propio Parque Nacional. El objetivo será fortalecer la oferta de alojamientos y otras actividades evitando la pérdida de valor añadido que hoy se fuga hacia las ciudades extremeñas más cercanas.

- Ampliar, diversificar y distribuir la oferta de áreas de uso público en el conjunto del área de influencia socioeconómica, ello redundará en el beneficio de todos y cada uno de los municipios.

\section{BIBLIOGRAFÍA}

ALVARADO, E. (2007): «Red Natura 2000 y espacios naturales protegidos en Extremadura. Ámbitos de gestión y participación entre la concertación y el conflicto», en $X X$ Congreso de Geógrafos Españoles. Universidad de Sevilla.

ASOCIACIÓN DE CIENCIAS AMBIENTALES (ACA) (2012): Estudio sobre la Calidad de la Información Ambiental Autonómica en la Red. Asociación de Ciencias Ambientales. Madrid, 57 pp. (http://www.cienciasambientales.org.es/docpublico/info/ EstudioInfoAmbiental.pdf)

AZQUETA, D. (1997): Valoración económica de la calidad ambiental. McGraw-Hill. Madrid.

BUENDÍA, J. y SOMUANO, F. (2003): «Participación electoral en nuevas democracias: la elección presidencial de 2000 en México», en Política y Gobierno, n X (2), pp. 289-323.

CÁNOVES G. et al. (2004): «Turismo rural en Cataluña y Galicia: Algunos problemas sin resolver», Cuadernos Geográficos, n 34 , pp. 111-128.

CARTA EUROPEA DE TURISMO SOSTENIBLE EN LOS ESPACIOS PROTEGIDOS (2007-2010). EUROPARC Federation, EUROPARC Consulting; Atelier Václav Hraba.

CEA D'ANCONA, M.A. (1998): Metodología cuantitativa. Estrategias y técnicas de investigación social. Síntesis, Madrid.

CEBRIÁN ABELLÁN, F. (Coord.) (2008): Turismo rural y desarrollo local. Universidad de Sevilla. Universidad de Castilla La Mancha, 330 pp.

CORRALIZA, J.A. et al. (2002): Los Parques Naturales en España: conservación y disfrute. Madrid, Fundación Alfonso Martínez Escudero y Ediciones Mundi-Prensa S.A., 491 pp.

DICK, A.S. y BASU, K. (1994): «Customer Loyalty: Toward an Integrated Conceptual Framework», Journal of the Academy of Marketing Science, vol. 22, n 2, pp. 99-113.

ENCUESTA DE OCUPACIÓN EN ALOJAMIENTO TURÍSTICOS. INE, 2012.

GARCÍA LÓPEZ, A. M. et. al. (2012): «Sostenibilidad en espacios naturales protegidos: El índice de ajuste territorial», Papeles de Geografía, n ${ }^{\circ} 55-56$, pp. 49-61.

GARCÍA MARÍN, R. (2011): «Turismo y desarrollo rural en la comarca del noroeste de la región de Murcia: Los programas europeos Leader», Cuadernos de Turismo, $\mathrm{n}^{\circ} 27$, pp. 419-435.

GÓMEZ, R. (2002). «Redes de información sobre las producciones locales. Saint - Denis Ciudad popular, dinámica y solidaria. Redes al servicio del desarrollo territorial 
integrado», en MÁRQUEZ, D. (coord.): Nuevos horizontes en el Desarrollo Rural. Universidad Internacional de Andalucía. Colección Sociedad, Cultura y Educación, 3. Akal. Tres Cantos. Madrid, pp. 105-129.

GREMLER, D.D. y BROWN, S.W. (1999): «The Loyalty Ripple Effect. Appreciating the Full Value of Customers», International Journal of Service Industry Management, vol. 10, no 3, pp. 271-293.

HARDIN, R. (1999): «Do we want Trust in Government? », en WARREN, M. (Ed.). Democracy and Trust. Cambridge University Press.

HARDIN, R. (2001): «Conceptions and Explanations of Trust», en COOK, K. S. (Ed.). Trust and Society. New York: Russell Sage Foundation.

HERNÁNDEZ, J.M. et al. (2011): «Agricultural diversification and the sustainability of agricultural systems: Possibilities for the development of agrotourism», Environmental Engineering and Management Journal, $\mathrm{n}^{\circ}$ 10-12, pp. 1911-1921.

HIDALGO-FERNÁNDEZ, A. et al. (2013): «Estimación del valor económico de La Sierrezuela y Los Villares», Cuadernos Geográficos, n ${ }^{\circ}$ 52, pp. 178-204.

HUMMEL, B. G. (2001): «Posibilidades en comunidad: lecciones aprendidas en Maquin», en RODRÍGUEZ, F. (Ed.). Manual de Desarrollo Local. Universidad de Oviedo. CeCodet. Trea. Gijón.

JAFARI, J. (2000): Enciclopedia del Turismo. John Wiley \& Sons, New York.

KOHLER, F.D. (2001): «El corporativismo local, ¿una estrategia de consenso para el desarrollo? », en RODRÍGUEZ, F. (Ed.). Manual de Desarrollo Local. Universidad de Oviedo. CeCodet. Trea. Gijón.

LECO, F. et al. (2010). Reserva Mundial de la Biosfera de Monfragüe. Caracterización geográfica y visión cartográfica. Cáceres, Ministerio de Medio Ambiente y Medio Rural y Marino. Universidad de Extremadura.

LECO, F. et al. (2012): «Análisis del capital social, la gobernanza y el desarrollo territorial en el Parque Nacional de Monfragüe y la Reserva Natural Garganta de los Infiernos», en FORONDA ROBLES, C. (Coord.). Capital social en espacios naturales protegidos. Universidad de Sevilla, pp. 259-325.

LECO, F. et al. (2013): «Rural tourist and their attitudes and motivations towards the practice of environmental activities such as agrotouris», International Journal of Environmental Research, vol. 7-1, pp. 255-264.

LOSCERTALES, B. (1999): «El turismo rural como forma de desarrollo sostenible. El caso de Aragón», Geographicalia, n 37, pp. 123-138.

MAURÍN ÁLVAREZ, M. (2005): «Los espacios naturales protegidos: lugar de encuentro entre sociedad y naturaleza, lugar para la Geografía», en Espacios públicos/ espacios privados. Un debate sobre el territorio. XIX Congreso de Geógrafos Españoles. A. G. E. y Universidad de Cantabria, Santander.

MAURÍN ÁLVAREZ, M. (2008): «Las áreas protegidas: un enfoque geográfico», Ería, $\mathrm{n}^{\circ} 76$, pp. 165-195.

MUÑOZ FLORES, J.C. (2008): «El turismo en los espacios naturales protegidos españoles, algo más que una moda reciente», Boletín de la Asociación de Geógrafos Españoles, $\mathrm{n}^{\circ}$ 46, pp. 291-304.

PASCUAL, J.A. (2007): La gestión del uso público en espacios naturales. Miraguano, Madrid. 
PILLET CAPDEPÓN, F. (2008): «Del turismo rural a la plurifuncionalidad en los territorios Leader y Proder de Castilla-La Mancha», en CEBRIÁN ABELLÁN, F. (Coord.) Turismo rural y desarrollo local. Ediciones de la Universidad de Castilla-La Mancha, pp. 187-198.

SABINO, C (1992): Metodología de la Investigación. Caracas: UCV.

SOTELO NAVALPOTRO, J.A. (2006): «Instrumentos para el estudio del medio ambiente: métodos para la valoración del coste ambiental», Estudios Geográficos, vol. LXVII, $\mathrm{n}^{\mathrm{o}} 260$, pp. 231-258.

TULLA PUJOL, A. et al. (2008): «Paisajes agrarios», en BUSQUETS, J. Y CORTINA, A. (Ed.). Manual de gestión del paisaje. Barcelona. Ariel.

VERA REBOLLO, J.F. y ESPEJO MARÍN, C. (2006): «El papel de los instrumentos de planificación en las dinámicas productivas y territoriales: las directrices y el Plan de Ordenación del Litoral de la Región de Murcia», en ROMERO, J. y FARINÓS, J. (Eds.): Gobernanza territorial en España: claroscuros de un proceso a partir del estudio de casos. València. Publicacions de la Universitat de València, pp. 61-79. 


\section{Anexo 1}

MODELO DE ENCUESTA

\begin{tabular}{|c|c|c|c|c|c|c|}
\hline \multicolumn{7}{|c|}{ LUGAR Y FECHA DE LA ENCUESTA } \\
\hline LUGAR & \multicolumn{3}{|l|}{ FECHA } & \multicolumn{3}{|c|}{ HORA } \\
\hline $\mathrm{N}^{\circ}$ COCHES & \multicolumn{3}{|c|}{$\mathrm{N}^{\circ}$ AUTOBUSES } & \multicolumn{3}{|c|}{$\mathrm{N}^{\circ}$ PERSONAS } \\
\hline \multicolumn{7}{|c|}{ DATOS DEL VISITANTE ENCUESTADO } \\
\hline \multicolumn{7}{|c|}{ 1.-Procedencia (Comunidad Autónoma o País, si es extranjero) } \\
\hline 2.- Edad & \multicolumn{2}{|l|}{ Menos de 30} & \multicolumn{2}{|c|}{$31-60$} & \multicolumn{2}{|c|}{ Más de 60} \\
\hline \multirow{3}{*}{ 3.- Profesión } & \multicolumn{2}{|l|}{ Estudiante } & \multicolumn{2}{|c|}{ Ama de Casa } & \multicolumn{2}{|c|}{ Jubilado } \\
\hline & \multicolumn{2}{|l|}{ Agrario } & \multicolumn{2}{|c|}{ Admón. } & \multicolumn{2}{|c|}{ Desempleado } \\
\hline & \multicolumn{2}{|l|}{ Educación } & \multicolumn{2}{|c|}{ Servicios } & \multicolumn{2}{|c|}{ Industria } \\
\hline 4.- $\mathrm{N}^{\circ}$ de veces que ha visitado Monfragüe & \multicolumn{2}{|l|}{1} & \multicolumn{2}{|c|}{$2-5$} & \multicolumn{2}{|c|}{ Más de 5} \\
\hline \multicolumn{7}{|c|}{ 5.- $\mathrm{N}^{\circ}$ de personas con las que viaja (incluido el entrevistado) } \\
\hline \multicolumn{7}{|l|}{ 6.- ¿En qué población se aloja? } \\
\hline \multirow{2}{*}{ 7.- ¿En qué tipo de alojamiento? } & Hotel & \multicolumn{3}{|c|}{ Casa rural } & \multicolumn{2}{|c|}{ Camping } \\
\hline & Hostal & Domicilio & io habi & tual & Casa $\mathrm{F}$ & liar \\
\hline 8.- $\mathrm{N}^{\circ}$ de noches & & & & & & \\
\hline 9.- Localidades de Monfragüe que ha visita & do (pasar por el & nunicipio $\mathrm{n}$ & no es & visitar o & nocer) & \\
\hline Casas de Millán & Casas de Mira & & & Casate & & \\
\hline Deleitosa & Higuera & & & Jaraice & & \\
\hline Malpartida de Plasencia & Mirabel & & & Romar & rdo & \\
\hline Saucedilla & Serradilla & & & Serrejc & & \\
\hline Toril & Torrejón el Rul & & & Villarr & S. Carl & \\
\hline Plasencia & Trujillo & & & Cácere & & \\
\hline RESEF & RVA DE LA & IOSFEI & $\mathbf{R A}$ & & & \\
\hline 10.- ¿Sabe qué es una Reserva de la Biosfer & & & & SI & NO & $\mathrm{NS} / \mathrm{NC}$ \\
\hline $\begin{array}{l}\text { 11.- ¿Pagaría más por un producto de la Re } \\
\text { calidad) }\end{array}$ & eserva de la Bio & fera? (sello & o de & SI & NO & $\mathrm{NS} / \mathrm{NC}$ \\
\hline 12.- ¿Pagaría más por un alojamiento en la & Reserva de la B & sfera? & & SI & NO & $\mathrm{NS} / \mathrm{NC}$ \\
\hline 13.- Razón por la que visita Monfragüe & & & & & & \\
\hline Conocer la Reserva & Conocer el Parc & & Conoc & er Extre & adura & Otras \\
\hline CAP & ACIDAD DF & CARG & & & & \\
\hline 14.- ¿Cuál es el motivo de la visita a esta ár & ea de uso públic & & & & & \\
\hline Recomendación Centro Visitantes & & & Vení: & de pas & & \\
\hline Interés turístico & & & Inter & és ornitc & gico & \\
\hline Ya lo conocía & & & Otra & & & \\
\hline 15.- ¿Encuentra elevado el $n^{\circ}$ de personas e & n esta área de us & público? & & SI & NO & $\mathrm{NS} / \mathrm{NC}$ \\
\hline 16.- ¿Encuentra elevado el $\mathrm{n}^{\circ}$ de vehículos & en esta área de $\mathrm{u}$ & o público? & & SI & NO & $\mathrm{NS} / \mathrm{NC}$ \\
\hline
\end{tabular}




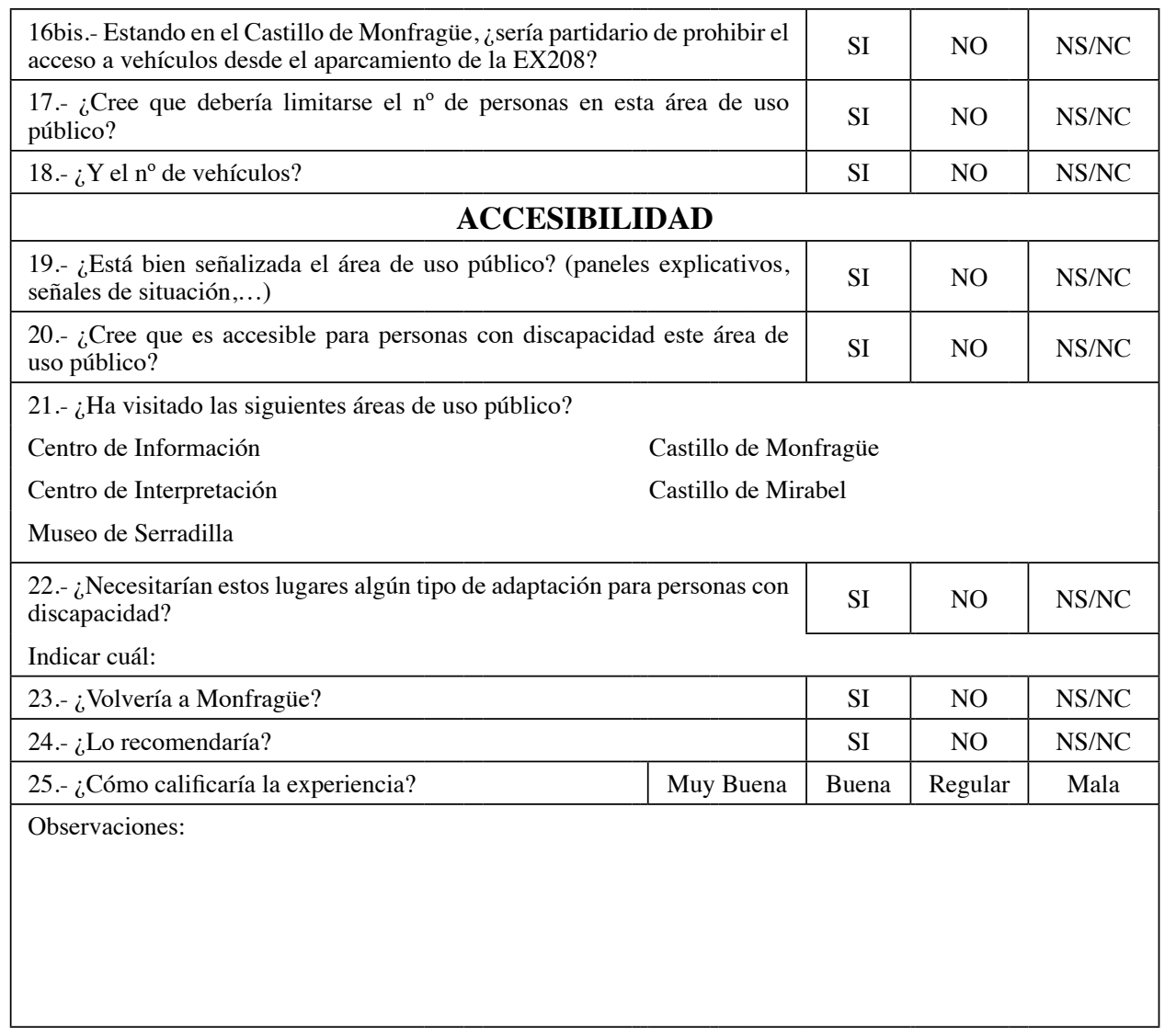


